\title{
Seropositivity in Dutch Crohn's disease patients against primed nude mouse lymph nodes, and the difference with lymphocytotoxic antibodies
}

\author{
A S PEÑA, INEKE KUIPER, H C WALVOORT, H W VERSPAGET, \\ IRENE T WETERMAN, E J RUITENBERG AND K M DAS
}

From the Department of Gastroenterology, University Hospital, Leiden, The Laboratory for Pathology, National Institute of Public Health and Environmental Hygiene, Bilthoven, The Netherlands, and the Albert Einstein College of Medicine, New York, NY, USA

SUMMARY Sera from patients with Crohn's disease have been reported to show positive immunofluorescence with lymph nodes of nude mice primed with a filtrate of intestinal tissue affected with Crohn's disease. An indirect immunofluorescence assay was used to test sera of 63 unrelated patients with Crohn's disease, 21 with ulcerative colitis and 36 control subjects against lymph nodes of athymic nude (nu/nu) mice which had been injected with Crohn's disease and ulcerative colitis intestinal tissue filtrates. Forty nine per cent of Crohn's disease patients, $10 \%$ of ulcerative colitis patients and 3\% of control sera reacted against lymph nodes of mice injected with intestinal tissue homogenate from Dutch Crohn's patients. With the lymph nodes of mice injected with ulcerative colitis intestinal tissue filtrates, $18 \%$ of Crohn's disease sera were positive, whereas all ulcerative colitis and control sera were negative. Lymph nodes from 18 of the 19 mice injected with Crohn's disease tissue filtrates reacted with Crohn's disease sera, whereas only three of these 19 mice reacted with ulcerative colitis sera. A comparative study, carried out in parallel with Crohn's disease filtrate induced hyperplastic lymph nodes from the Bilthoven colony (W2) and from the New York colony (E671) using sera from 54 Crohn's disease patients from Leiden, showed immunoreactivity with 44 and $57 \%$ of the Crohn's disease sera against the two hyperplastic lymph nodes. Thirty six of the 54 Crohn's disease sera $(67 \%)$ reacted with either or both lymph nodes. Only $11 \%$ of the Crohn's disease sera which were examined for immunofluorescence and lymphocytotoxic antibodies had lymphocytotoxic antibodies, whereas $40 \%$ and $46 \%$ of the same sera showed positive immunofluorescence against E671 and W2, respectively. Absorption studies indicated that lymphocytotoxic antibodies activity and the immunofluorescence against the primed nude mouse lymph node are mediated by different serum antibodies in Crohn's disease. The reproducibility of the nude mouse immunofluorescence test system for a preferential immunoreactivity of Crohn's disease sera against Crohn's disease tissue primed murine lymph nodes has been confirmed by the present study. Further studies are necessary to find out whether crossreactive antigen(s) as recognised by some of the Crohn's disease sera in mice injected with ulcerative colitis tissue filtrate is similar to the antigen(s) detected by Crohn's disease sera in mice injected with Crohn's disease tissue filtrates.

Fifty four years after its first description, ${ }^{2}$ the aetiology and pathogenesis of Crohn's disease remains elusive. Das and his colleagues reported that Crohn's disease tissue filtrates injected into athymic

Address for correspondence: Dr A S Peña, Department of Gastroenterology, Building 1, C4-P, Room 016, University Hospital, 2333 AA Leiden. The Netherlands.

Received for publication 1 April 1986 nude mice (nu/nu) produce lymphoma and lymphoid hyperplasia with lymphoid cells containing antigen(s) recognised by Crohn's disease sera..$^{34}$ These authors recently reported the appearance of a 'Crohn's disease-specific antigen' in normal and hyperplastic lymph nodes of nu/nu mice three to four months after the animals were injected with Crohn's disease tissue filtrate. ${ }^{5}$ The antigen appears 
to be localized mainly in B cell lineage cells and at times in macrophages.'.

Several investigators ${ }^{7-10}$ have reported that between $22-64 \%$ of the sera of patients with inflammatory bowel disease showed lymphocytotoxic antibodies against lymphocytes from healthy control subjects and Crohn's disease patients. The present study was designed to test the reproducibility of the nude mouse model system and in addition to determine whether the antibodies involved in lymphocytotoxic antibodies are the same as those directed against nude mouse lymphoid cells primed with Crohn's disease tissue filtrate.

\section{Methods}

SERUM SPECIMENS

One hundred and twenty serum samples were collected from patients attending the Department of Gastroenterology of the Leiden University Hospital and healthy controls. The sera derived from 63 unrelated patients with Crohn's disease, 21 with ulcerative colitis, and 36 healthy subjects (nine laboratory assistants and 27 blood donors).

Disease activity of patients with Crohn's disease was classified according to Crohn's disease activity index $(\mathrm{CDAI})^{11}$ values and clinical assessment by the attending gastroenterologists. Patients with ulcerative colitis were diagnosed by the attending gastroenterologist on the basis of symptoms, sigmoidoscopic and radiological findings according to Truelove and Witts. ${ }^{12}$

\section{MOUSE COLONY}

The lymph nodes of athymic nude mice (nu/nu) were obtained from two sources: The National Institute of Public Health and Environmental Hygiene, Bilthoven and The Albert Einstein College of Medicine, New York. Nude mice with Balb/c background (Bomholtgard, Denmark) from the former institute were injected, according to the protocol of Das et al. ${ }^{45}$ The mice were kept in germ free isolators with appropriate precautions with respect to food and water. Of the material received from Albert Einstein College of Medicine, New York, one of the hyperplastic lymph nodes was used which had developed in a Balb/c nude mouse after injection of Crohn's disease tissue filtrate during the current Crohn's disease experiments. ${ }^{45}$

From the Bilthoven colony 19 nude mice $(40$ lymph nodes) injected with Crohn's disease intestinal tissue homogenate from three different patients $(\mathrm{W}, \mathrm{S}, \mathrm{V})$, four nude mice (eight lymph nodes) injected with ulcerative colitis tissue homogenate from one patient (B) and one control nude mouse (non-injected) (three lymph nodes) were tested.
The animals from the Bilthoven colony were killed between 2.5 months and 14 months after injection of tissue filtrates. Cryostat sections $(4 \mu \mathrm{m})$ of the lymph nodes were used for an indirect immunofluorescence assay with sera from Crohn's disease, ulcerative colitis and control subjects according to methods described in detail elsewhere. ${ }^{5}$ In brief, the serum samples were coded, absorbed with normal mouse serum proteins covalently coupled with $\mathrm{CN}-\mathrm{Br}$ activated Sepharose-4B, and centrifuged before the immunofluorescence study. Lymph node sections were fixed with 95 parts of ice chilled ethanol $(100 \%)$ and five parts acetic acid $(96 \%)$, incubated with absorbed serum samples for 60 minutes, washed and incubated for another 60 minutes with fluorescein isothiocyanate conjugated antihuman IgG (gamma chain specific) (Cappel Laboratories, Inc, Cochranville, Pennsylvania, USA), (1:30-1:90). Known positive and negative control sera obtained from New York were included during each set of experiments. The sections were mounted in a glycerol mixture, composed of nine parts of glycerol with $2.5 \%$ 1,4-diazabicyclo $(2,2,2)$ octane, $97 \%$ (DABCO) and one part phosphate buffer saline ( $\mathrm{pH} \mathrm{8.6)} \mathrm{to} \mathrm{avoid} \mathrm{fading} \mathrm{of}$ immunofluorescence, as described by Johnson et al. ${ }^{13}$

The sections were examined under an immunofluorescence microscope independently by at least two investigators without knowledge of the source of sera and scored according to the scale described elsewhere $^{+}$with a minor modification. $(0=$ no fluorescence, $+/-=$ possibly negative, and $+=$ definitely positive; $+/-$ scores were counted as negative during the final scores).

Table 1 Results of indirect immunofluorescence test performed with nude mouse lymph nodes from nude mice injected with Crohn tissue, ulcerative colitis tissue and non-injected using sera from $C D, U C$ patients and healthy controls

\begin{tabular}{|c|c|c|c|c|c|c|c|c|}
\hline \multirow[t]{2}{*}{ Sera } & \multicolumn{2}{|c|}{$\begin{array}{l}\text { Nude mice } \\
C D\end{array}$} & \multicolumn{3}{|c|}{$\begin{array}{l}\text { Nude mice } \\
\text { UC }\end{array}$} & \multicolumn{3}{|c|}{$\begin{array}{l}\text { Nude mice } \\
\text { non-injected }\end{array}$} \\
\hline & +- & $\begin{array}{l}\% \\
\text { (pos) }\end{array}$ & + & - & $\begin{array}{l}\% \\
\text { (pos) }\end{array}$ & + & - & $\begin{array}{l}\% \\
\text { (pos) }\end{array}$ \\
\hline $\begin{array}{l}\mathrm{CD} \\
(\mathrm{n}=63) \\
U \mathrm{C}\end{array}$ & $31 * 32$ & $(49)$ & $5^{*}$ & 23 & (18) & 0 & 22 & (0) \\
\hline $\begin{array}{c}(n=21) \\
\text { Control } \\
(n=36)\end{array}$ & $2 * 19$ & $(10)$ & 0 & 18 & (0) & 0 & 6 & $\begin{array}{l}\text { (0) } \\
(0)\end{array}$ \\
\hline
\end{tabular}

${ }^{*} \mathrm{p}<0 \cdot(001$ 
LYMPHOCYTOTOXIC ANTIBODIES

Thirty five Crohn's disease sera, absorbed with mouse serum proteins were screened against a panel of $\mathrm{B}$ and $\mathrm{T}$ lymphocytes of eight healthy volunteers with different HLA phenotypes, and the presence of lymphocytoxic antibodies was detected by the double colour flourescense technique according to van Rood et al. ${ }^{14}$ The dead lymphocytes were stained with propidium iodine and read by an automated fluorescence microscope according to Bruning et

Table 2 Clinical and laboratory data of 54 patients with Crohn's disease. The Crohn's disease activity index (CDAI) and the results of indirect immunofluorescence against E671 and W2 are shown

\begin{tabular}{|c|c|c|c|c|c|c|c|}
\hline$N$ & Sex & Age & Localisation & Resection & $C D A I$ & $E 671$ & $W 2$ \\
\hline 1 & $\mathbf{M}$ & 37 & lleum-caecum & + & 40 & & + \\
\hline 2 & $\mathbf{F}$ & 45 & Ileum & + & 114 & - & + \\
\hline 3 & $\mathbf{F}$ & 43 & Caecum-colon & + & 244 & & + \\
\hline 4 & $\mathrm{~F}$ & 55 & Duod-ileum-colon & + & 114 & - & + \\
\hline 5 & $\mathrm{~F}$ & 40 & Ileum & + & 204 & & + \\
\hline 6 & $\mathrm{~F}$ & 44 & Ileum & + & 91 & + & - \\
\hline 7 & $\mathbf{M}$ & 47 & Ileum-colon-rectum & - & 171 & - & - \\
\hline 8 & $\mathbf{F}$ & 36 & Ileum-colon & + & 251 & - & - \\
\hline 9 & $\mathbf{F}$ & 19 & Ileum-colon & - & 433 & & + \\
\hline 10 & $\mathbf{M}$ & 66 & Ileum-colon & + & 108 & - & + \\
\hline 11 & $\mathbf{F}$ & 25 & Colon & - & 60 & + & \\
\hline 12 & $\mathbf{F}$ & 37 & Colon & - & 0 & & - \\
\hline 13 & $\mathbf{M}$ & 32 & Colon & + & 35 & - & + \\
\hline 14 & $\mathbf{M}$ & 31 & Ileum-colon & + & 162 & & + \\
\hline 15 & $\mathbf{M}$ & 47 & Ileum-caecum & + & 97 & - & - \\
\hline 16 & $\mathbf{F}$ & 25 & Ileum-colon & + & 142 & + & + \\
\hline 17 & $\mathbf{F}$ & 38 & Ileum & + & 42 & & + \\
\hline 18 & $\mathbf{M}$ & 27 & Colon & - & 73 & & - \\
\hline 19 & $\mathbf{M}$ & 36 & Ileum & + & 2 & - & + \\
\hline 20 & $\mathbf{M}$ & 13 & Ileum & - & 88 & & - \\
\hline 21 & $\mathbf{F}$ & 36 & Ileum-colon & + & 228 & + & - \\
\hline 22 & $\mathbf{F}$ & 26 & Ileum & + & 126 & + & + \\
\hline 23 & $\mathbf{M}$ & 39 & Ileum & + & 14 & + & + \\
\hline 24 & $\mathbf{F}$ & 20 & Ileum & + & 109 & + & - \\
\hline 25 & $\mathbf{M}$ & 35 & Colon & - & 38 & - & - \\
\hline 26 & $\mathbf{F}$ & 50 & Duod-jej & + & 112 & - & + \\
\hline 27 & $\mathbf{F}$ & 22 & Stomach-duod-jej-il & - & 25 & - & - \\
\hline 28 & $\mathrm{~F}$ & 21 & Stomach-colon-rectum & - & 172 & - & + \\
\hline 29 & $\mathbf{M}$ & 29 & Ileum-colon & - & 107 & - & - \\
\hline 30 & $\mathbf{M}$ & 37 & Jej-ileum-colon & + & 20 & & - \\
\hline 31 & $\mathbf{M}$ & 33 & Colon & - & 24 & + & - \\
\hline 32 & $\mathbf{F}$ & 31 & Ileum-colon & + & 0 & - & - \\
\hline 33 & $\mathbf{M}$ & 35 & Ileum-colon-rectum & + & 161 & + & - \\
\hline 34 & $\mathbf{M}$ & 41 & Ileum-colon & + & 35 & - & + \\
\hline 35 & $\mathrm{~F}$ & 27 & Colon & - & 16 & & + \\
\hline 36 & $\mathbf{M}$ & 48 & Ileum-colon & + & 308 & & + \\
\hline 37 & $\mathbf{F}$ & 49 & Ileum & - & 149 & + & + \\
\hline 38 & $\mathbf{F}$ & 33 & Colon & + & 30 & & - \\
\hline 39 & $\mathbf{F}$ & 32 & Ileum-caecum & + & 11 & & + \\
\hline 40 & $\mathbf{F}$ & 29 & Colon & - & 131 & - & \\
\hline 41 & $\mathbf{M}$ & 25 & Ileum & + & 24 & + & - \\
\hline 42 & $\mathbf{M}$ & 27 & Ileum & + & 170 & + & + \\
\hline 43 & $\mathbf{M}$ & 35 & Ileum-rectum & + & 36 & + & + \\
\hline 44 & $\mathbf{F}$ & 28 & Ileum-colon & - & 216 & + & + \\
\hline 45 & $\mathbf{M}$ & 31 & Jej-ileum & + & 17 & - & - \\
\hline 46 & $\mathbf{M}$ & 46 & Ileum & + & 165 & - & - \\
\hline 47 & $\mathbf{M}$ & 61 & Ileum-colon & + & 65 & & - \\
\hline 48 & $\mathbf{M}$ & 34 & Ileum-colon-rectum & + & 41 & - & + \\
\hline 49 & $\mathbf{M}$ & 32 & Ileum-colon & - & 273 & - & - \\
\hline 50 & $\mathbf{F}$ & 21 & Ileum & - & 112 & - & + \\
\hline 51 & $\mathbf{M}$ & 41 & Ileum-colon & + & 73 & + & - \\
\hline 52 & $\mathbf{F}$ & 40 & Ileum-caecum & + & 24 & & + \\
\hline 53 & $\mathbf{F}$ & 48 & Ileum & + & 75 & + & - \\
\hline 54 & $\mathbf{M}$ & 57 & lleum & + & 44 & - & - \\
\hline
\end{tabular}


$a l .{ }^{15}$ Twenty six sera were re-examined for lymphocytotoxic antibodies without prior absorption with mouse immunoglobulins revealing no effect on the lymphocytotoxic antibodies activity by this procedure.

\section{Results}

From the Bilthoven mouse colony, 18 of the 19 nude mice injected with Crohn's disease-tissue filtrates showed lymph node positivity with Crohn's disease sera, whereas only three of these 19 mice reacted with ulcerative colitis sera. Table 1 shows that $49 \%$ of sera from patients with Crohn's disease were positive in the immunofluorescence test against lymph nodes of the nude mice injected with Crohn's disease tissue filtrates $(p<0 \cdot 001)$, whereas only two of the 21 sera from ulcerative colitis patients and one of the 36 control subjects gave a positive reaction against the lymph nodes injected with Crohn's disease tissue filtrates. Five of 28 Crohn's disease sera and none of the ulcerative colitis and normal control sera reacted against the lymph nodes of the mice injected with ulcerative colitis tissue. All sera, including Crohn's disease sera, did not react with the lymph nodes from the uninjected mouse. The antigen(s) recognised by the sera of patients with Crohn's disease appear to be present in axillary

Table 3 Results of indirect immunofluorescence test performed with nude mouse lymph nodes from New York (E671), Bilthoven (W2) and sera from Dutch CD and UC patients and controls

\begin{tabular}{lcll}
\hline & & $\begin{array}{l}\text { E671 } \\
\%\end{array}$ & $\begin{array}{l}W 2 \\
\% \\
\text { Subjects }\end{array}$ \\
& $(n)$ & $\begin{array}{l}W \\
(p o s)\end{array}$ & \\
\hline CD Active & $(14)$ & 44 & 57 \\
UC Remission & $(40)$ & 41 & 54 \\
Controls & $(11)$ & 9 & 9 \\
\hline
\end{tabular}
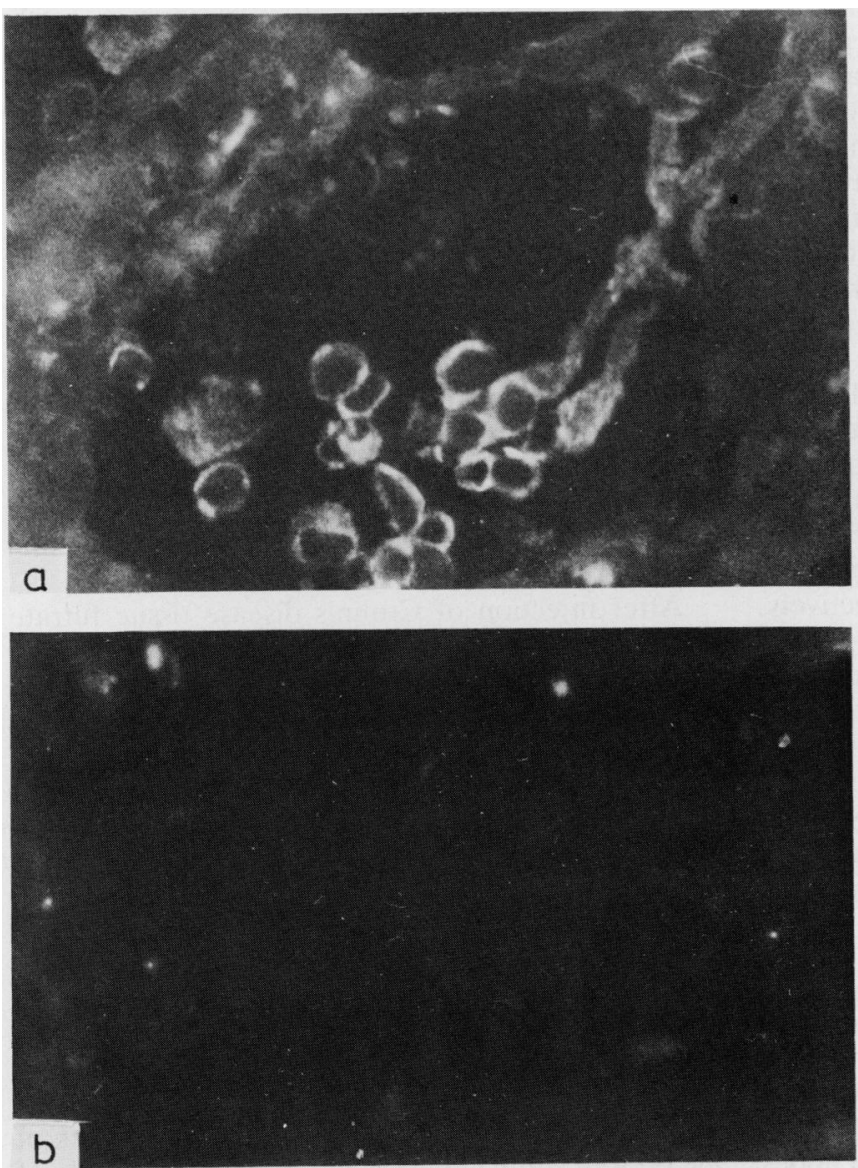

Figure Sections of a hyperplastic lymph node of a mouse (W2) injected with ileal tissue filtrate from a patient with Crohn's disease, showing: (a) immunofluorescence produced by Crohn's disease serum, and note intense cytoplasmic staining of groups of cells localised mainly in the medulla. (b) the absence of immunofluorescence in serum from another Crohn's disease patient. 
lymph nodes of the injected nude mice as well as in mesenteric or inguinal lymph nodes.

The results of the indirect immunofluorescence assay performed with the sera from 54 patients with Crohn's disease, 11 with ulcerative colitis and nine control subjects from Leiden against the hyperplastic lymph nodes from W2 mouse from the Bilthoven colony were compared with those observed against hyperplastic lymph nodes (E671) obtained from New York (Table 2). Forty four per cent of the sera from patients with active Crohn's disease (CDAI $>150)$ reacted with the E671 lymph node and $57 \%$ with the W2 lymph node (Tables 2 and 3 ). The immunofluorescence reactivity of the sera of Crohn's disease patients in remission against E671 and W2 was 41 and $54 \%$, respectively. Thirty six of the 54 Crohn's disease sera $(67 \%)$ reacted with either or both lymph nodes (Table 2). There was no correlation of the immunoreactivity with site of disease or previous resection (Table 2). As shown in Table 3, no correlation was observed between the immunofluorescence results and activity of Crohn's disease. Only one of the 11 ulcerative colitis sera from a patient with total colitis gave positive immunofluorescence with both the E671 and W2 lymph nodes. None of the nine healthy controls showed immunoreactivity against the lymph nodes.

Figure 1 shows the fluorescence pattern of W2 tested with two Crohn's disease sera. With one of the sera, cytoplasmic immunofluorescence was observed in groups of cells localised in the medulla, whereas the other Crohn's disease serum did not stain.

Table 4 shows the comparison of immunofluorescence and lymphocytotoxic antibodies results in 35 Crohn's disease sera which were examined for both. Only four of $35(11 \%)$ had lymphocytotoxic antibodies against $\mathrm{B}$ and $\mathrm{T}$ cells, whereas 14 of $35(40 \%)$ and 16 of $35(46 \%)$ showed positive immunofluorescence against E671 and W2, respectively. Three of the four Crohn's disease sera which demonstrated lymphocytotoxic antibodies were also positive for immunofluorescence against the W2 lymph node. These four Crohn's disease sera with positive lymphocytotoxic antibodies and three additional immunofluorescence positive (but lymphocytotoxic antibodies negative) Crohn's disease sera were absorbed with human platelets and lymphocytes and retested for lymphocytotoxic antibodies and immunofluorescence against the lymph nodes. After such absorption, lymphocytotoxic antibodies disappeared whereas the immunofluorescence did not.

Table 5 shows a two-by-two contingency table with the comparison of immunoreactivity between Crohn's disease sera and E671 and W2 lymph nodes
Table 4 Results of indirect immunofluorescence test performed with nude mouse lymph nodes from Bilthoven (W2) and New York (E671) and lymphocytotoxic antibodies ( $L C A$ ) in CD sera

\begin{tabular}{|c|c|c|c|c|c|c|}
\hline \multirow[b]{2}{*}{ Patients } & \multicolumn{2}{|l|}{ E67I } & \multicolumn{2}{|l|}{$W 2$} & \multicolumn{2}{|l|}{$L C A$} \\
\hline & +- & $\begin{array}{l}\% \\
\text { (pos) }\end{array}$ & +- & $\begin{aligned}- & \% \\
& (p o s)\end{aligned}$ & +- & $\begin{array}{l}\% \\
\text { (pos) }\end{array}$ \\
\hline $\mathrm{CD}$ & 1421 & $1 \quad(40)$ & 161 & $19(46)$ & $4^{*} 31$ & (11) \\
\hline
\end{tabular}

${ }^{*}$ Three of the sera also displayed positive immunofluorescence with W2 lymph node.

Table 5 Two-by-two contingency table showing the comparison of immunoreactivity between $C D$ sera and E671 and W2 lymph nodes

\begin{tabular}{rrrr} 
& & W2 & \\
& + & - \\
7 & 8 \\
E671 & & \\
& - & 10 & 11 \\
\hline
\end{tabular}

Fisher's exact test: $p=0 \cdot 61$.

suggesting that the immunoreactivity of the Crohn's disease sera are directed against more than one antigenic determinant present in the lymphoid tissues.

\section{Discussion}

The uniqueness of the T-cell deficiency in the athymic nude mouse has led to the use of these animals for studies of several species of microorganisms that are difficult to grow in conventional animals. These include viruses, bacteria, and mycobacteria. ${ }^{16-19}$

After injection of Crohn's disease tissue filtrate into nude mice, Das and his colleagues found development of lymphoma and benign lymphoid hyperplasia, which by an indirect immunofluorescence assay showed reaction with sera from other Crohn's disease patients. ${ }^{5}$ Of 52 sera from their Crohn's disease patients, $54 \%$ showed this immune recognition, whereas one of the sera from 19 ulcerative colitis patients gave positive immunofluorescence. All sera from other specific diarrheal subjects and normal controls were negative. This observation suggested that it would be possible to develop a diagnostic serological test for Crohn's disease. This requires confirmation by other centres, however, particularly with the use of patients from a different geographical area. The results of the present study in Dutch patients confirms some of 
the earlier observations, notably $49 \%$ of the Crohn's disease sera showed positive immunofluorescence with Crohn's disease intestinal tissue injected mice. When the same Crohn's disease sera were examined against the lymph nodes from two centres, $67 \%$ of the sera reacted with either or both the lymph nodes. We found that five of 28 Crohn's disease sera, however, reacted with some of the lymph nodes from mice injected with ulcerative colitis intestinal tissue, and two of the 21 ulcerative colitis sera with Crohn's disease primed lymph nodes, suggesting the presence of crossreactive materials in the lymphoid tissue from mice injected with ulcerative colitis and Crohn's disease tissue filtrates. Further absorption studies may help to clarify this crossreactivity.

In the comparative study, 44 and $57 \%$, respectively, of the Crohn's disease sera from patients with active disease, gave positive immunofluorescence with the lymph nodes from New York and Bilthoven mice $(\mathrm{nu} / \mathrm{nu})$ injected with Crohn's disease filtrates.

There was no correlation between the clinical activity of Crohn's disease and positive immunofluorescence pattern, a divergence from the results obtained in New York, where a significantly positive correlation was found between CDAI and the immunofluorescence. ${ }^{5}$ This difference might have been because of the patient population. Most of the patients studied in Leiden were ambulatory and seen as outpatients, whereas in the New York study, ${ }^{5}$ the majority of the patients had been admitted and were presumably more symptomatic cases. In a separate study with ambulatory patients, Das et al, reported $50 \%$ positivity of nu/nu lymphoma with Crohn's disease sera. ${ }^{20}$ Another possibility could be differences in interpretation of the CDAI values by both centres.

Some patients with Crohn's disease may not have antibodies against the lymphoid cells of the nude mice, but non-reactivity of some of the sera against both the lymph nodes may be due to either variation of antigen(s) and/or antibody concentrations or presence of antibodies directed against a separate antigenic determinant, as suggested by the results shown in Table 5 .

Crohn's disease tissue contains at least three distinct immunoreactive proteins which react with Crohn's disease sera. ${ }^{21}$ Whether all of the three proteins are derived from a single molecule or agent or from more than one source is unclear. Whether these proteins are indeed the same antigen or antigens present in the nude mouse lymphoid tissue is also unknown.

The cause of the lymphadenopathy in nu/nu mouse after injection of Crohn's disease filtrate is unknown. The published findings suggest that anti- gen(s) recognised by Crohn's disease sera are present in certain groups of mononuclear cells present in normal and hyperplastic lymph nodes. ${ }^{56}$

Occasional ulcerative colitis sera crossreact with Crohn's disease tissue filtrate injected nu/nu lymph node as shown in previous ${ }^{5}$ and the current studies. Similarly, crossreactivity was noted with a small percentage of Crohn's disease sera against the ulcerative colitis tissue filtrate injected nu/nu lymph node. Whether the crossreactivity can be removed by double absorption of the sera (second absorption with normal nu/nu spleen cells) as reported by Williams $e t a l^{4}$ remains to be determined.

Several investigators have reported the presence of lymphocytotoxic antibodies in 22 to $64 \%$ of the sera from Crohn's disease patients. We have shown here that the antibody reacting with nu/nu lymphoid cells could not be related to the lymphocytotoxic antibodies. When the same group of sera was used in an automated, standardised test system for lymphocytotoxic antibodies, only four of $35(11 \%)$ of the sera showed lymphocytotoxic antibodies activity whereas 24 of $35(69 \%)$ of the same sera reacted with both Crohn's disease injected lymph nodes (Table 2). The percentage of lymphocytotoxic antibodies was lower than those mentioned in previous reports, ${ }^{7-10}$ but the present panel of normal lymphocytes was smaller, and the sera for studying lymphocytotoxic antibodies activity were selected on the basis of positivity with the immunofluorescence test. Futhermore, when several immunofluorescence positive sera and the four sera with lymphocytotoxic antibodies, three of which showed positive immunofluorescence with $\mathrm{W} 2$, were absorbed with human platelets and lymphocytes, the lymphocytotoxic antibodies disappeared but the immunofluorescence pattern was unchanged; in fact, the fluorescence was even brighter after absorption. These results indicate that the immunoreactivity of the Crohn's disease sera against the nu/nu mouse lymphoid tissue is not related to human lymphocytotoxic antibodies activity.

Recently, Das et al, reported that $28 \%$ of sera from first degree relatives and spouses of Crohn's disease patients, but not in those of ulcerative colitis patients, reacted with murine lymphomas induced by Crohn's disease filtrates. ${ }^{20}$ These observations are similar in respect to Crohn's disease but different in terms of ulcerative colitis, to those concerning lymphocytotoxic antibodies and RNA antibodies detected in both Crohn's disease and ulcerative colitis patients, and some of the members of their family and spouses. ${ }^{22}{ }^{23}$ The possibility remains that the specificity detected by Crohn's disease sera in the nude mice is somehow related to the same immunoregulatory defect or to the presence of 
anti-idiotype antibodies specific for Crohn's disease. In this context, it may be relevant that Ginsburg et $a l^{24}$ have shown the occurrence of increased numbers of monoclonal $\mathrm{B}$ lymphocytes in the peripheral blood of some inflammatory bowel disease patients. These B lymphocytes might be responsible for the production of specific antibodies which would induce related Crohn's disease-associated idiotype in nu/nu mice.

Further studies are needed to characterise the antigen(s) present in the nu/nu lymphoid tissue recognised by Crohn's disease sera. Athymic nude mice appear to be an interesting model for studies of the pathogenesis of Crohn's disease and may offer possibilities for the development of a diagnostic test system.

This investigation was supported in part by a research grant NIADDK AM 26403 from the National Institutes of Health, USA. We like to thank I Biemond for data processing. We are also indebted to Anneke Elgersma, C Moolenbeek, and $\mathrm{P}$ de Jong and colleagues for biotechnical help; Dr F $\mathrm{H}$ J Claas, J. Parlevliet, and colleagues for lymphocytotoxic antibodies studies and Anna Caponigro and Karlien Kruijer for their excellent secretarial assistance. We also would like to thank Mrs I. Seeger for reading the English text.

The study was in part presented at the annual meeting of the American Gastroenterological association, New York 1985 and is published in an abstract form. ${ }^{\prime}$

\section{References}

1 Peña AS, Kuiper I, Walvoort HC, Ruitenberg EJ, Das KM. Reproducibility of a potential serodiagnostic system in Crohn's disease using primed nude mouse lymph nodes and the difference with lymphocytotoxic antibodies. [Abstract] Gastroenterology 1985; 88: 1536A.

2 Crohn BB, Ginsburg L, Oppenheimer SD. Regional ileitis. A pathological and clinical entity. JAMA 1932; 99: 1323-9.

3 Das KM, Valenzuela I, Morecki R. Crohn's disease lymph nodes homogenates produce murine lymphoma in athymic mice. Proc Natl Acad Sci USA 1980; 77: $588-92$

4 Williams SE, Valenzuela I, Kadish AS, Das KM. Glomerular immune complex formation and induction of lymphoma in athymic nude mice by tissue filtrates of Crohn's disease patients. J Lab Clin Med 1982; 99: 827-37.

5 Das KM, Valenzuela I, Williams SE, Soeiro R, Kadisch AS, Baum SG. Studies of the etiology of Crohn's disease using athymic nude mice. Gastroenterology 1983; 84: 364-74.
6 Das KM, Valenzuela I, Zuckerman M, Williams SE, Kadish A. Time course of appearance of Crohn's disease associated antigen(s) in athymic nude mouse lymph nodes following injection of Crohn's disease tissue filtrates. [Abstract]. Gastroenterology 1984; 86: 1057.

7 Korsmeyer S. Strickland RG, Wilson ID, Williams RC. Serum lymphocytotoxic and lymphocytophilic antibody activity in inflammatory bowel disease. Gastroenterology 1974; 67: 578-83.

8 Strickland RG, Friedler EM, Henderson CA, Wilson ID, Williams RC. Serum lymphocytotoxins in inflammatory bowel disease. Clin Exp Immunol 1975; 21 : 384-93.

9 Kuiper I, Weterman IT, Biemond I, Castelli RC, Rood van JJ, Peña AS. Lymphocytotoxic antibodies in patients with Crohn's disease. In: Peña AS, Weterman IT, Booth CC, Strober W. Recent advances in Crohn's disease. Developments in gastroenterology. Vol. I. The Hague: Martinus Nijhoff, 1981: 234-47.

10 Brown DJC, Jewell DP. Cold reactive lymphocytotoxins in Crohn's disease and ulcerative colitis. I. Incidence and characterization. Clin Exp Immunol 1982; 49: $67-74$.

11 Best WR, Becktel JM, Singleton JW, Kern Jr. F. Development of a Crohn's disease activity index. Gastroenterology 1976; 70: 439-44.

12 Truelove SC, Witts LJ. Cortisone in ulcerative colitis. Final report on a therapeutic trial. Br Med J 1955; ii: 1041-8.

13 Johnson GD, Davidson RS, McNamee KC, Russell G, Goodwin D, Holborow EJ. Fading of immunofluorescence during microscopy: a study of the phenomenon and its remedy. J Immunol Meth 1982; 55: 231-42.

14 Rood van JJ, Leeuwen van A, Ploem JS. Simultaneous detection of the two cell population by two-colour fluorescence and application to the recognition of B cell determinants. Nature 1976; 262: 795-6.

15 Bruning JW, Claas FHJ, Kardol MJ, Lansbergen Q, Naipal AM, Tanke HJ. Automated reading of HLA-A, $\mathrm{B}, \mathrm{C}$ typing and screening. The propidium iodine (PI) method. Hum Immunol 1982; 5: 225-31.

16 Wyde PR, Couch RB, Mackler BF, Cate TR, Levy $\mathrm{BM}$. Effects of low- and high-passage influenza virus infection in normal and nude mice. Infect Immun 1977; 12: 221-9.

17 Underwood GE, Weeds SD. Recurrent cutaneous herpes simplex in hairless mice. Infect Immun 1974; 10: 471-4.

18 Emmerling $\mathrm{P}$, Finger H, Bockmuhl J. Listeria monocytogenes infection in nude mice. Infect Immun 1975; 12: 437-9.

19 Prabhakaran K, Harris EB, Kirchheimer WF. Hairless mice, human leprosy and thymus derived lymphocytes. Experientia 1975; 31: 784-5.

20 Das KM, Simon WR, Weinstock JV, Valenzuela I, Marcuard SMP. Serum antibodies from Crohn's disease patients and their household members react with murine lymphomas induced by Crohn's disease tissue filtrates. J Lab Clin Med 1986; 107: 95-100.

21 Bagchi S, Das KM. Detection and partial characterization of Crohn's disease tissue specific protein recog- 
nised by Crohn's disease sera. Clin Exp Immunol 1984; 55: 41-8.

22 Dehoratius RJ, Strickland RG, Miller WC, Volpicelli NA, Gaeke RF, Kirsner JB, Williams RC. Antibodies to synthetic polyribonucleotides in spouses of patients with inflammatory bowel disease. Lancet 1978; i: 1116-9.

23 Strickland RG, Miller WC, Volpicelli NA, Gaecke RF.
Wilson ID, Kirsner JB, Williams Jr. RC. Lymphocytotoxic antibodies in patients with inflammatory bowel disease and their spouses - evidence for a transmissible agent. Clin Exp Immunol 1977; 30: 188-92.

24 Ginsburg CH, Ault KA, Falchuk ZM. Monoclonal B lymphocytes in the peripheral blood of patients with inflammatory bowel disease. Gastroenterology 1981; 81: $1111-4$. 